\title{
استقلالية البنك المركزي وتأثرها بالمالية العاهة
}

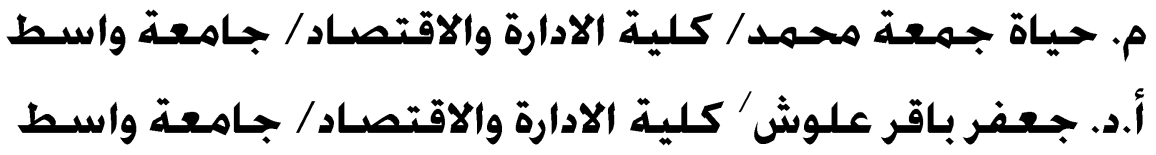

أوضحت الدراسة أن المالية العامة لها تأثير على عمل البنك المركزي أستقلاليته وذلك من خلال جملة من المتغيرات النقاية كالتضخم

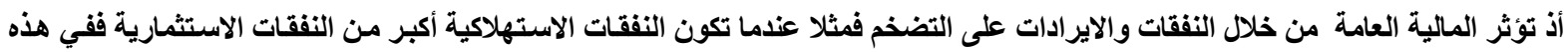
الحالة سوف تؤدي المالية العامـة من خلال أحد ادواتها على رفع معدلات التضخم وكذلك في مزاد العملة أذ يلاحظ في الدول الريعية تكون الايرادات النفطية تثكل نسبة كبيرة من موازنة الدولة العامة وتسيطر عليها وزارة المالية (الحكومة) أي تسيطر على العملة الاجنبية (الدولار)

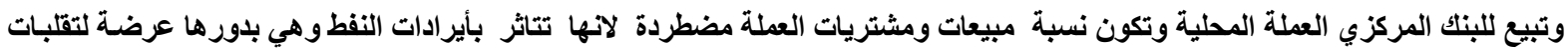
اسعار النفط العالمية.

\section{$\underline{\underline{\text { Abstract }}}$}

The study showed that the public finances have an impact on the work of the Central Bank and its independence through a number of monetary variables such as inflation, which affect the public finances through expenditure and revenue on inflation, for example when the consumption expenditure is greater than investment expenditure in this case will lead public finances through one of its tools To raise inflation rates .As well as in the auction of currency is noted in the rent countries are oil revenues constitute a large proportion of the state budget and controlled by the Ministry of Finance (the government) which controls the foreign currency (dollar) and sells to the Central Bank of the local currency and the proportion of sales and purchases of currency steady because it is affected by oil revenues In turn vulnerable to fluctuations in global oil prices

الاقدمة

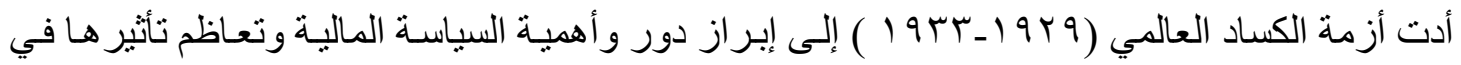

النشاط الاقتصادي، مما أعطى المبررات للتذخل الحكومي في الحياة الاقتصسادية، اذ أن الأفكار الكلاسيكية أثبتت فثـلها في ذلك الوقت في معالجـة أزمـة الكسـاد العـالمي التي طالت النظام الر أسـمالي في ذلك الوقت، ممـا حدا بالاقتصـاديين إلى البحث عن الحلول حتى وإن كانـ تتـاقض مـع ثوابـت النظريـة الكلاسيكية، لذلك كان الحل المنقذ للفكر الكلاسيكي هو الحلول التي جاء بها الاقتصادي الانكليزي جون مينارد كينز. وبسبب تلك الطروحسات التدخلية ازدادت هيمنة السياسة المالية سنة بعد أخرى على الحيـاة الاقتصـادية بشكل عـام وعلى السياسـة النقديـة بشكل خاص، هذه الهيمنة الواسعة من قبل الحكومة متمثلة بسياستها المالية بدأت تظهر كمعوق أساسي أمسام رفع معدلات النمـو ومكافحـة التضـخم و البطالـة أو مـا يعرف (بالتضـخم الركودي)، إذ ازدادت معدلات البطالـة ومـا ير افقها مـن زيـادات أكبر في معدلات التضـخم، بسبب التوسـع في المعروض النقدي و التمويـل المستمر لعجز الموازنة العامة .

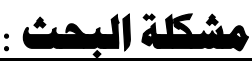

يُعد مفهوم الهيمنة المالبـة مفهومـاً معاكساً لمفهوم أستقلالية البنك المركزي بمعنى أن العلاقة عكسية بينهما كلما كانت هنالك درجة عالية لاستقلالية البنك المركزي كلما دل ذلك على أن درجة الهيمنة المالية منخفضـة 
،و العكس صـحيح .ونتيجـة لازديـاد تـذخل الحكومـة في الحيـاة الاقتصـادية ازدادت هيمنـة السياسـة الماليـة ، هذه الهيمنة الواسعة للحكومـة المتمنلـة بسياستها المالية بدأت تظهر كعائق اسـاس أمام رفع معدلات النمو ومكافحـة

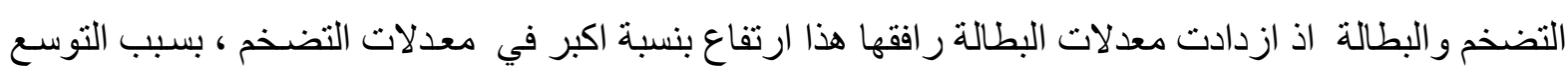
في المعروض النقدي الى جانب ارتفاع كبير في الدين العام بسبب التمويل المستمر لسد عجز الموازنة. أستند البحث إلى فرضيتن رئيسيتين هما الفرضية الأولى: أن الهيمنـة المالية خـلال سنوات البحث أدت الىى أضـعاف قدرة البنك المركزي على استخدام ادو اته بكفاءة وتخفيض فرص تحقيق الاهداف النقدية . الفرضية الثانية : -تأثير الهيمنة المالية على مسار ات النمو في الناتج المحلي الاجمالي .

أهد|ف البمث :تهدف الدر اسة إلى : توضيح وتحليل مفهوم الهيمنة المالية و أثر ها على أستقلالية البنك المركزي و النمو الاقتصادي.

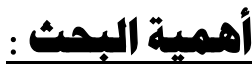

يبرز دور وأهميـة الدراسـة من خـلال توضيح الآثار السلبية التي يمكن أن تسببها الهيمنة المالية على المتغير ات الاقتصادية الكلية المتمثلة في ارتفاع المستوى العام للأسعار ، و الذي يمكن أن يؤدي إلى تشو هات في الادخـار والاستثمار، و انخفاض في معدلات نمو النـاتج القومي وزيـادة الفقر و البطالة، وكذلك الحد من كفـاءة أدوات السياسة النقدية في معالجة هذه المشاكل.

\section{هيكابة البمث: (ف)}

لغرض التوصل الى نتائج رصينة تم تقسيم البحث الى محورين رئيسيين: تتاول المحور الاطار المفاهيمي لاستقلالية البنك المركزي في حين استعرض المحور الثاني أثر المالية العامة على بعض المتغير ات النقدية

\section{المور الاول/ الاطار المغاهيمي لاستقلالية البنك المركزي}

أولاً: مفهوم الاستقلالية The Concept Of Independence

نادى كثير من الاقتصـاديين بضرورة استقلال البنك المركزي من الحكومة نظر المـا ادى اليه خضو عه التام للسلطات الحكوميـة من افر اطها في الاقتر اض منـه ومـا ترتب على ذلك تدهور عملات كثير من الدول خصوصا في المدة التي انقضت بين الحربين العالميتين ،كما ان البنك المركزي على الرغم من احتكاره لإصدار

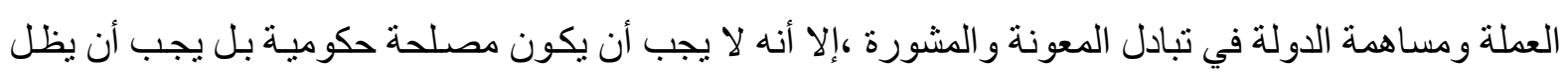

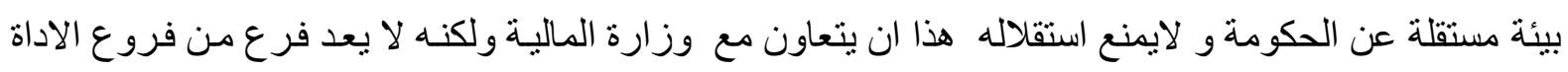

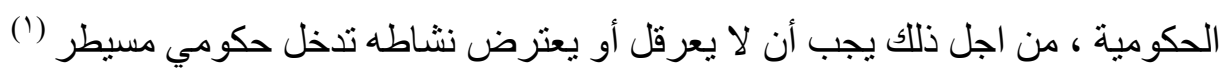


فيقصد باستقلالية البنك المركزي (Central Bank independence) أن تكون إدارة السياسـة النقديـة

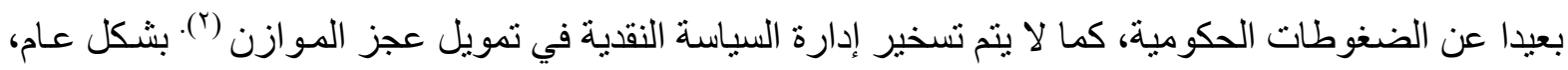
يقصد باستقلالية البنك المركزي Central Bank Independence ، انفصاله عن الحكومة، وهو مفهوم مشـابه لاستقلالية القضاء. فالمؤسسة المستقلة هي التي تحدد أهدافها وتتخذ قرار اتها من دون تدخل من الجهاز السياسي (السلطة التنفيذية (َّ). كما تعني الاستقلالية أن يكون البنك المركزي مفوضـاً وحده بالعمل على تحقيق استقرار

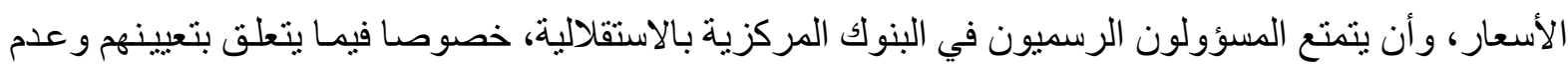

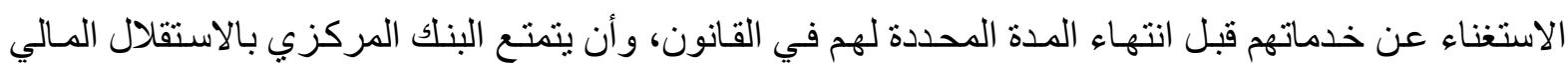

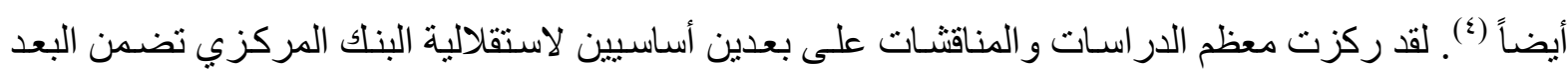
الاول الخصائص المؤسسية التي تعزل البنك المركزي عن التأثثر السياسي في تحديد اهداف السياسـة النقدية ،في حين ركز البعد الثاني على ابر از تلك الجو انب التي تمنح البنك المركزي الحريـة في تتفيذ سياسته النقديـة سعيا لتحقيق اهدافه المنشودة (0). ثانياً: أنواع وشروط وخصائص استقلالية البنك المركزي. أولاً: أنواع استقلالية البنوك المركزية.

ا ـ الاستقلالية في تحديد الأهداف (").

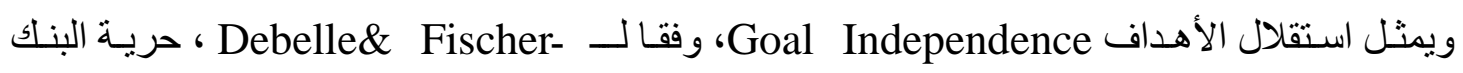
المركزي في تحديد الأهداف النهائية Final Objectives، أذ ستكون البنوك المركزيـة أكثر استقلالاً اذا كان هدف استقرار الأسعار هو الهدف الأسمى لها، وبذلك فإن تعريف استقلال الأهداف يستبعد الضغوط السياسية التي يمكن ان ترتبط بتنفيذ السياسة النقدية.

r الاستقلالية في تحديد الأدوات (v).

فيعني حريـة البنـك المركزي في اختيـار الأدوات المناسبة لتحقيق الأهداف النهائيسة، فـلا يكون البنك

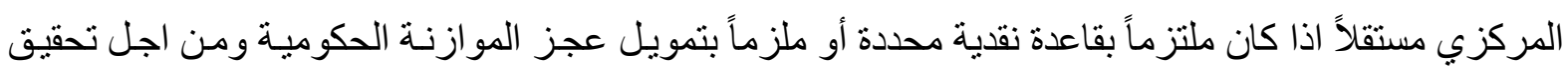
الهدف الرئيس للبنوك المركزية و هو المحافظة على استقرار الأسعار والعملة ، يجب استعمال عدة أدوات

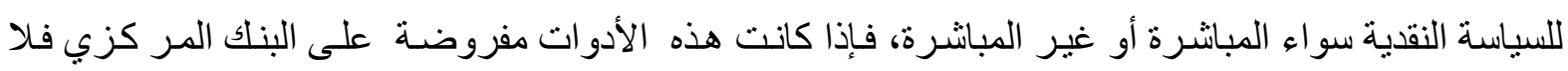

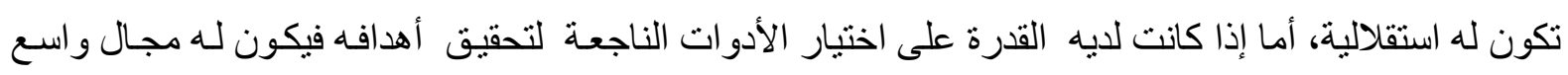
من الاستقلالية.

وبـالطبع فـإن الاستقلالية التي تسـعى إليهـا البنـوك المركزيـة حاليـا ترتكز أساسـاً على إعطائهـا حريـة

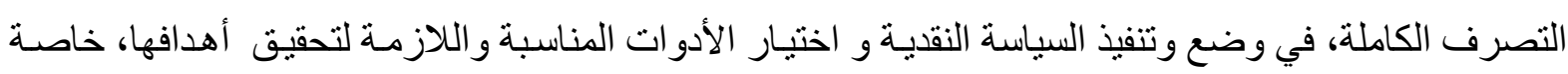
وأن الهدف الرئيس قد تحدد بالفعل وانحصر في ضرورة تحقيق استقر ار الأسعار و المحافظة على قيمـة العملة، و يجدر بنا التنويه إلى أن استقرار الأسعار ينقسم إلى استقر ار داخلي (المستوى العام للأسعار) واستقر ار خـارجي (سعر الصرف) مع وجود علاقة تأثير قوية و متبادلة بينهما، فارتباط استقلالية السلطة النقدية بهدف الاستقرار 
الداخلي و الخارجي للأسعار إنما ينبع من التعارض الذب يحدث بين السياسـة الماليـة و السياسـة النقديـة من جهة نتيجة لميل الحكومة لتمويل عجز الميز انية تمويلا تضخمياً، و التعـارض الذي ينشـأ بين سياسـة سعر الصرف وف و السياسة النقدية من جهة أخرى نتيجة لقيام الحكومة بتحديد أهداف لسعر الصرف (يمنحها القانون في معظم دول العالم الحق في تحديد سياسـة سـعر الصـرف) تتعـارض مـع أهداف السياسـة النقديـة التـي يضعها البنك المركزي

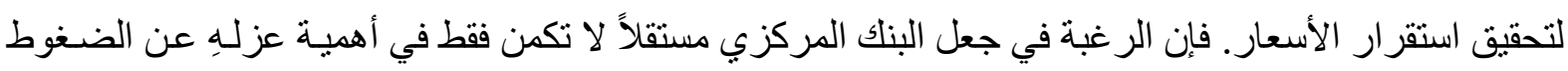

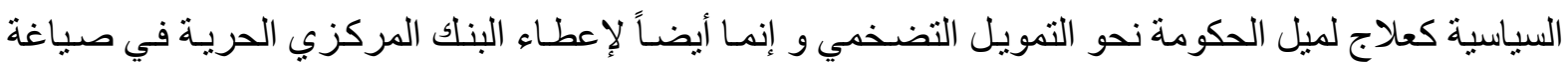
السياسة النقدية من خلال إدارة القاعدة النقدية أذ يصبح قادراً على رفض تنفيذ سياسـة سعر الصـرف التي تضعها التهاء الحكومة و التي قد يترتب عنها نتائج تضخمي (1)

\section{ثانياً: شروط استقلالية البنوك المركزية.}

في ضو اءلمفاهيم المتعددة لاستقلالية البنوك المركزيـة. إلا أن هناك ثناثة شروط مسبقة لاستقلالية البنوك المركزي(؟). الشرط الأول: يجب أن يكون هناك أطسار قانوني وتنفيذي يحدد بشكل واضح تسبر عليه السياسة النقدية، ففي ظل الإطار القانوني ينبغي تحديد استقلالية البنوك المركزية لتجنب أي تعارض مـع الحكومـة يؤدي إلى عدم تحقيق الأهداف المرسومة للسياسـة النقديـة. ويجب على البنك المركزي أن يثير إلى مـا يريد تحقيقه من أهداف من خلال أدو اته المستخدمة. الثرط الثاني :الثفافية ويقصد بها إن تقوم البنوك المركزيـة بفتح المجـال للحكومـة والجمهور الاطلاع على بر امج السياسـة النقديـة بصـورة مستمرة ، بصـورة تنظيم نشـاطات بين البنك المركزي و الحكومـة وأيضـا مساءَلة البرلمان لثرح الأهداف المعلنة للسياسة النقدية والأدوات التي يستعملها البنك المركزي ليكون الجمهور على اطلاع دائم حول التغيرات و التطور ات التي تحدث في السياسة النقدية. الثـرط الثالث: إنشـاء إطسار مؤسسـي فعـال. أي تنفيذ القرارات المتعلقة بالسياسـة النقديـة من دون تدخل الحكومة.

\section{وتكمن فعالية البنوك المركزية في أن تتمتع بالاستقلالية في أربع نواح (").} أ- الاستقلال الإشر افي: ويقصد به القوانين أو الإجر اءات التي يتم وضعها لكي تحمي المشرفين

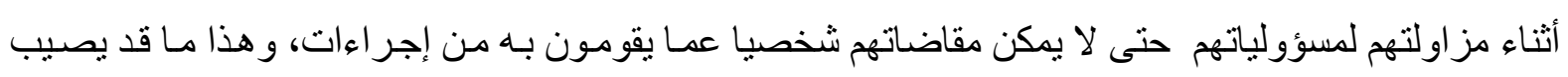
عملية الأشر اف بالثلل كما أن قيام البنك المركزي بدفع أجور مناسبة يودى إلى جذب الموظفين الأكثر كفاءة

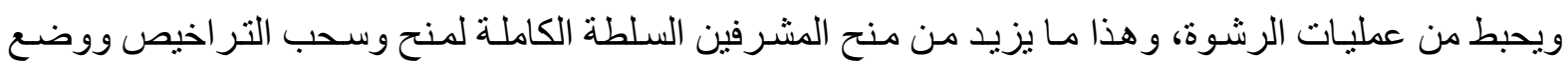
القو اعد الملائمة.

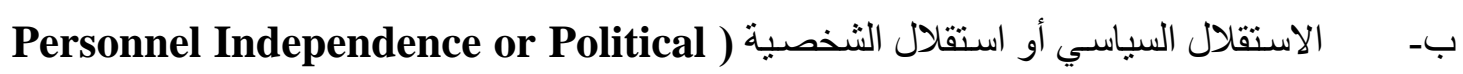
Independence): ويقصد به أنّ نفوذ الحكومة في إجراءات التعين و الإقالة في البنك المركزي قد تكون جزئيسة أو مستبعدة تمامـاوتحديد الهيكل التنظيمسي وكذللك تحديد الأدوار لأعضـاء مجلس الإدارة و الثـفافية في الإسي 
تـ - الاستقلال المالي FIN FINCIAL INDEPENDENCE) و والمقصود به مدى قدرة

البنك المركزي من منع الحكومة للحصول على القروض المباشرة وغير المباشرة من البنك المركزي.

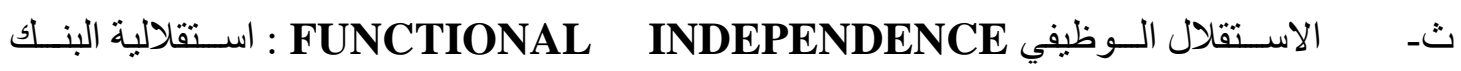

المركزي ليست غاية في حد ذاتها، بل وسيلة لتحقيق الهدف المحدد وينبغي إن يحدد الهدف بوضوح و أنّ يعلو هذا الهدف على الأهداف الأخرى. فاستقلالية البنك المركزي تعمل على تحقيق أهداف السياسـة النقدية ممـا يمنح السلطة النقية الامتياز عن السلطة السياسية، فالبنك المركزي المستقل يقوم بنشر البيانات و الإحصـاءات المالية و النقدية للجمهور بمنطق الثفافية من أجل انضباط النظام في رسم السياسة النقدية وفي تنفيذها.

ثالثاً: خصائص الاستقلالية من خصائص الاستقلالية التي تتمتع بها البنوك المركزية عدم إتباعها لسلطة إدارية حكومية تتلقى منها الأوامر و التعليمات ، و عدم قابلية المحافظ ونو ابه للعزل، وأنّ تكون للبنك المركزي ميز انية مستقلة ، وأنّ تتوفر لها جميع السبل و الإمكانات لانتهاج السياسة النقدية التي تحقق الاستقرار النقدي و المحافظة على قيمة العملـة (ء). أنّ الدر اسات الكثيرة و المستفيضـة لفلسفة الاستقلالية خرجت بخصـائص عديدة ومن هذه الدر اسـات هي دراسـة التي أوضحت مجموعة من الخصـائص التي تعد ضرورية لوصف الاستقلالية وقد (Hawells and Bain)

استعملت اغلب معايير أو مقاييس الاستقلالية بالاستناد إلى الخصائص الآتي ('). أـ- الضمانات التشريعية للاستقلالية وعدم وجود العقبات والعر اقيل. بـ- التحديد القانوني لأهداف البنك المركزي وطبيعة تلك الأهداف. ت- طرق التعبين للمحافظ ونو ابه ومجلس الإدارة و إقالتهه. ث- طول المدة الوظيفية للمحافظ. ج- وجود أو عدم وجود ممثل للحكومة في مجلس الإدارة. ح- مدى التز ام البنك المركزي بتعليمات الحكومة ومدى قدرة البنك للتصرف بأدو اته. خ- حدود تمويل البنك المركزي للحكومة. د- قدرة الحكومة على تغير أية خاصية من النقاط أعلاه من قبل الحكومة. ثالثاً: مبررات ومحددات استقلالية البنك المركزي. ا - مبررات استقلالية البنوك المركزية. أ. إن الثـؤون المتعلقة بالنقد ينبغـي إبعادهـا عن نفوذ السياسيين نظر الأن أعضـاء الحكومـة و البرلمـان

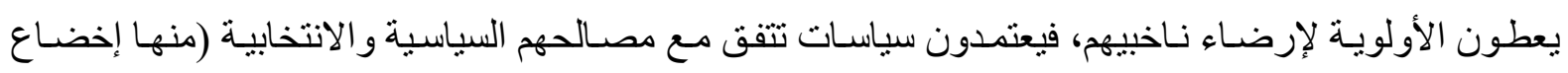
البنك لضغوط سياسية تتعلق بانتهاج سياسة نقدية توسعية قبيل الانتخابـات) ولكنها تضر بقيمـة النقود وترفع من معدل التضخم، لذا ينبغي إسناد أمر هذه الثؤون إلى بنك مركزي مستقل عن الحكومة) (r). 
ب. إن قدرة البنك المركزي على تحقيق، والإبقاء على، الاستقرار طويل الأجل للأسعار ، سوف تتحسن اذا كانت صياغة السياسة النقدية بأيدي مسؤولين بعيدين عن السياسة يكون باستطاعتهم النظر الى المدى الطويل. تـ إذا كان البنك المركزي مستقلا فإن السياسـة التي يتبعها في هذه الحالـة سوف تؤدي الى انخفاض التضخم واستقر ار مستويات الأسعار. وقد استتد هذا الفهم إلى العديد من الدراسات التي بحثت العلاقة بين درجـة استقلالية البنوك المركزية والتضخم، وانتهت الى وجود علاقة عكسية بينهما خاصـة في البلدان المتقدمـة، بمعنى

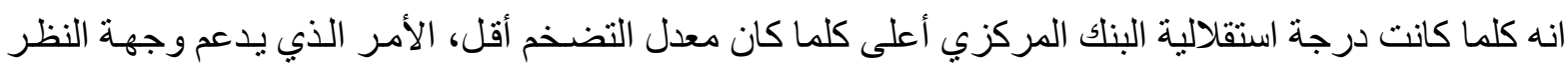
القائلة بأن توفير درجة أعلى من الاستقلالية للبنك المركزي يساعد على تخفيف عبء التضخم وزيادة مصداقية

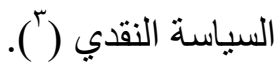

د. الارتباط بين استقلالية البنوك المركزية وبين استقرار الأسعار بوصفه الهذف الرئيس للسياسة النقدية (؛). ذ ـ تستطيع البنوك المركزيـة ذات الدرجة العاليـة من الاستقلالية مقاومـة طلبـات الحكومـة لتمويل عجز

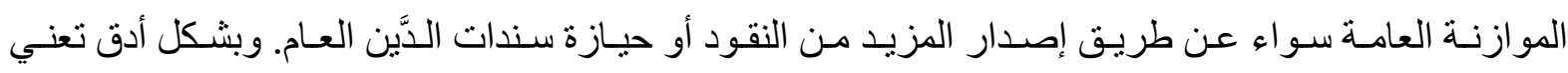
استقلالية البنك المركزي عن الحكومة في هذا السياق ان الأخيرة لا تستطيع إجبار البنك المركزي على تمويل العجز في الموازنة العامة (o). ح. إن استقلالية البنك المركزي ستؤدي إلى إبعاد تـأثنير ات الحكومـة عن هذه البنوك فيما يتعلق بتحديد نفقاتها و إير اداتها، ومن ثم فصل موازنة البنك المركزي عن الموازنة العامة للدولة (ج). خ.تُناط بالبنك المركزي مسؤولية مر اقبة وتوجيه النظام المالي في الدولة، وكذلك إيجاد التنسيق المطلوب بين مؤسساته المختلفة، مما يتطلب تمتع البنك المركزي بالاستقلالية (V). ر. إنّ الأمور المتعلقة بالنقود يجب إبعادها عن نفوذ السياسيين لان أعضـاء الحكومـة والبرلمـان يعطون

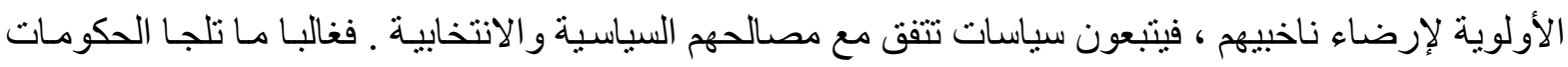

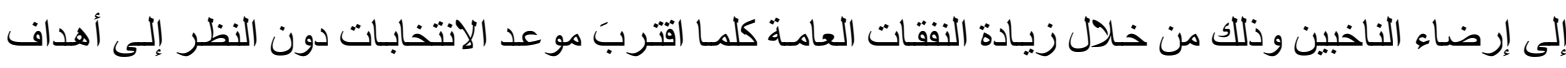
السياسة النقدية مطلقا (^). ز. إن تزايـد عولمـة الأسـواق الماليــة واقتر انهـا بالأزمـات الماليـة المتكـررة، يسـتدعي اسـتقلالية البنـك المركزي في التصدي لهذه الأزمات من خلال استخدام الأدوات النقدية المناسبة ('). ثانياً: محددات استقلالية البنوك المركزية

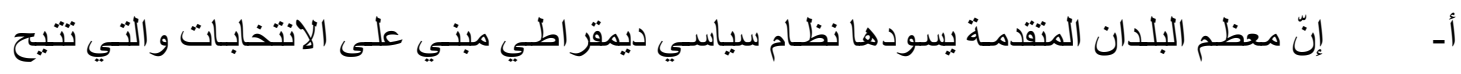
للمو اطنين اختيار الأفضل من بين المرشحين و إذا كان أداؤهم لا يلبي رغبة الجماهير فسوف يتم اختيار غير هم في الانتخابات المقبلة ، لذا فمن الأجدر القادة المنتخبون هم صانعوا السياسة الاقتصـادية بمـا فيها السياسـة النقديـة،

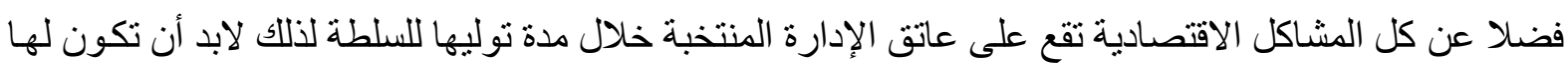
السيطرة على السياسة النقدية بوصفها إحدى تلك السياسات. 
ب- تعارض الاستقلالية مع بعض القضايا السياسية الخطيرة (؟)

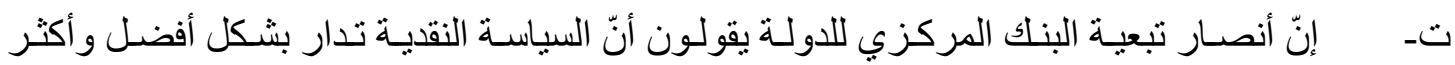
فعاليـة إذا كانت مندمجـة بالسياسـة الاقتصـادية للحكومـة ، فمثنا السياسـة الهادفـة إلى الحفـاظ على استقرار قيمـة العملة قد تتعارض مع أهداف اقتصادية مهية مثل تحقيق النمو وتأمين العمالة الكاملة و غير ها (ب).

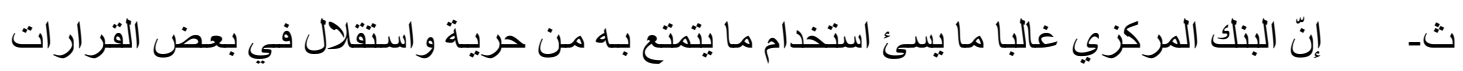

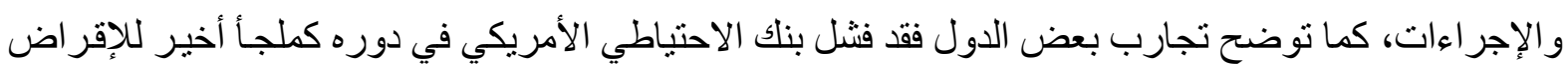

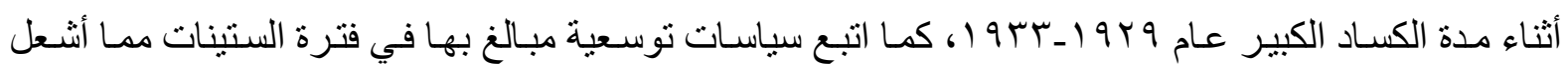
نير ان التضخم (๕)

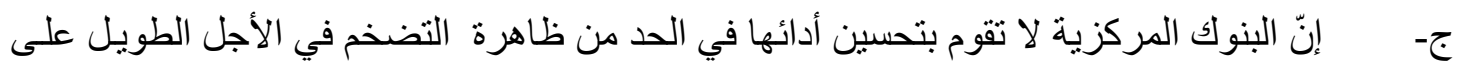

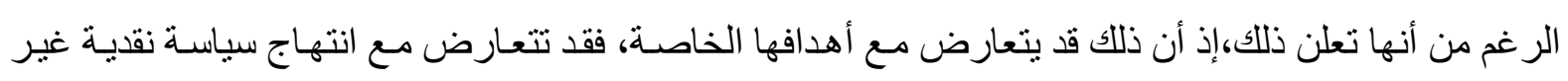
تضخمية ، فموقف البنوك يتأثر بـالمواقف السياسية ودرجـة خضو عه لهذه المؤثرات ، وهذا بثير الثكوك حول

مصداقية البنوك المركزية واستقلاليتها في معالجة التضخم أو قد تميل سياستها للتضخم لتماتل سياسة الدولة (0). ح- قد تحظى بعض البنوك المركزية بدرجة استقلالية اقل من مثيلتها في البنوك المركزيـة الأخرى لكن أداءها يكون أفضل في تحقيق استقر ار الأسعار، مثنلا يعد البنك المركزي اليابـي أقل استقلالا من البنك

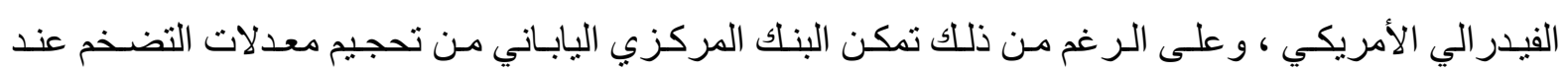
مستويات اقل من المستويات في الاحتياطي الأمريكي كذلك البنك الفرنسي كان أقل استقلالا من البنك المركزي الألماني فقد استطاعت فرنسا من جعل التضخم أقل من ألمانيا (†). رابعاً:- معايير ودوافع ومقاييس استقلالية البنك المركزي

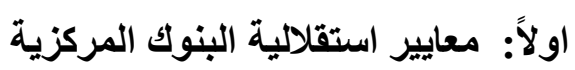
هنالك مجمو عة من المعايير التي تتحدد على أساسها درجة استقلالية البنك المركزي و هي ما يأتي. تواجه الدراسات المعنية باستقلالية البنوك المركزيـة صسعوبة كبيرة خاصـة في قياس درجة الاستقلالية، نظر الأن هذه الأخيرة بطبيعتهـا لا يمكن قياسـها كميـا بشكل دقيق لمـا يحكمها من عو امل تشـمل أحكامـا قيميـة ونسبية، مع ذلك اتفقت معظم الدراسـات التي أجريت في موضوع استقلالية البنك المركزي على مجموعة من

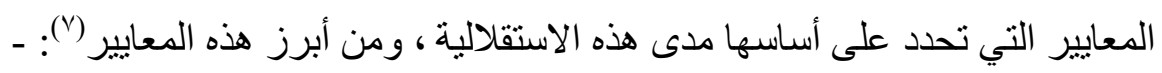

\section{أ-رسم السياسة النقدية.}

تختلف الجهة المسؤولة عن وضع وتحديد السياسـة النقديـة بـاختلاف درجة الاستقلالية التي يتمتع بها البنك المركزي، ذلك أن البنك المركزي المستقل لديه صلاحيات لوضع وتحديد السياسة النقدية بمقتضى التفويض الذي منحه لـه القانون بحريـة من دون ان يتلقى أي تعليمات أو توجيهات من الحكومـة. في حين تكون السياسـة النقية في حالات أخرى من مسؤولية الحكومة، حيث تتولى الأخيرة تقريريها وتحديد أهدافها. 


\section{ب- أهاف البنك المركزي.}

يتمتع البنك المركزي باستقلالية أكبر حين يناط له وفقاً للقانون عدد محدد من الأهداف، ويؤشر إسناد

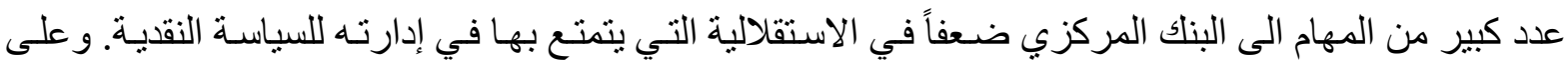
العكس من ذلك فإن تحديد مهمة البنك المركزي بشكل دقيق، مع التركيز و التأكيد على تحقيق الاستقرار في القيمة الداخلية والخارجية للعملة، يعد من أهم المؤشر ات الدالة على استقلالية هذا البنك عن الحكومة.

\section{ت_التمثيل الحكومي في إدارة البنك المركزي.}

يؤثر تكوين مجالس إدارات البنوك المركزية تأثثر اً كبير اً على طبيعة العلاقة بين البنوك و الحكومـات، ففي بعض الحالات تعد هذه المجالس بمثابة قناة رسمية للحكومة لممارسـة تأثثر هـا بصورة مباشـرة على قر ارات البنك المركزي. وفي كثير من الدول تقوم الحكومـة بتعيين معظم، إن لم يكن كل، أعضـاء مجلس إدارة البنك المركزي. الأمر الذي يمكن الحكومة من ممارسة تأثثر ها من خلال وجودها المباثر في تللك المجالس. وقد يتمتع ممثلو الحكومة بكافة حقوق بقية الأعضـاء بمـا في ذلك حق التصويت على قرارات البنلك المركزي مـا يمنحهم قدرة اكبر في التأثير على قرارات البنك وسياساته.

\section{ث_حدود البنك المركزي في تمويل الحكومة.}

وضعت معظم البلدان قيودا مشـددة على إمكانية اقتر اض الحكومـة مـن بنوكها المركزيـة، خشية ان يؤدي الإفر اط في الاقتر اض الى التضخم. وتمثل هذه القيود احد المظاهر العامـة للاستقلالية التي يتمتع بها البنك المركزي في تحديده وتنفيذه للسياسة النقدية. وقد منعت اتفاقية ماسترخت عام بو 99 بصورة قاطعة تمويل عجز الموازنـة في الدول الأعضـاء عن طريق اللجوء الـى الاقتـر اض مـن البنلك المركزي، وبدأت، بالفعل، الدول

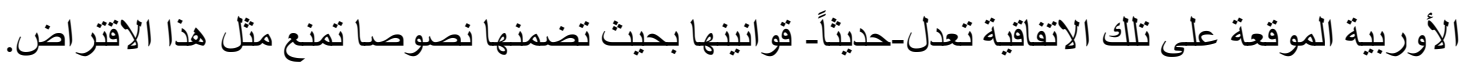

\section{ج-حرية استخدام الأدوات النقدية.}

إن عدم قدرة البنك المركزي على استخدام أدوات السياسة النقدية التي ير اها مناسبة، ومن دون حاجة للحصول على مو افقة الحكومة، يضعف من استقلالية البنك المركزي. وتتفاوت قدرة البنك المركزي على استخدام أدوات السياسـة النقدية بين الدول تفاوتا ملحوظا، ففي بعض منها يتمتع هذا البنك بحرية كبيرة في مجال استعمال تللك الأدوات وفي بعضهـا الآخر يتطلب مجرد تغيير بعض منها مثل تغيير منطلبات الاحتياطي القانوني على سبيل المثال الرجوع إلى الحكومة.

\section{خ-الاستقلال المالي للبنك المركزي.}

يحتل موضوع الاستقلال المالي للبنك المركزي أهمية خاصـة في در اسـة علاقـة هذا البنك بالحكومـة ومدى استقلاله عنها، فاثتر اط الحصول على موافقة مسبقة من الحكومـة على مو ازنـة البنك المركزي قد يشكل في حد ذاته وسيلة غير مباثرة تستعملها الحكومة للتأثير على قرارات البنك المركزي، وذللك عن طريــق الحـــ

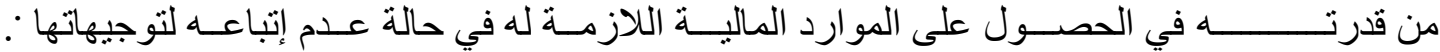

\section{خ- سلطة الحكومة في تعيين وعزل إدارة البنك المركزي.}

في معظم بلدان العالم يتم إسناد مهمة تعيين محافظ البنك المركزي وكبار مسؤوليه الى السلطة التنفيذية (الحكومـة) و لا يتعـارض ذلك مـع استقلالية البنك. ومعنى ذلك ان الاستقلالية لا تتعـارض مـع قيام الحكومـات 
بتعيين محافظ البنك المركزي و أعضاء الهيئات العليا في هذا البنك. غير انهه في الدول التي تتمتع فيها البنوك المركزية بدرجة عالية من الاستقلالية، نجد ان السلطات الحكومية تخضع لقيود ومحددات في مجال تعيين و إقالة

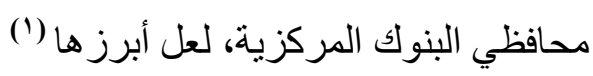

ضرورة وجود نسبة من التعيينـات لا تتو لاهـا الحكومـة، وذلك بهدف الحد من نفوذ الحكومـة في هذا

المجال ومنعها من الانفر اد بكافة التعيينات.

Y) تحديد مدة البقاء في المنصب بحيث تكون طويلة نسبيا مقارنة بالدورة الانتخابية، وذلك للتقليل من تأثير الحكومة على مجلس إدارة البنك المركزي. r) يشترط الحصول على مو افقة البرلمان (السلطة التشريعية في البلد) عند قيام الحكومة بتعيين كبار المسؤولين في البنك المركزي.

\section{المهور الثاني/ أثر المالية العامة على بعض المتفيرات النقدية}

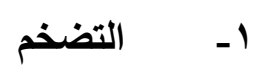

تتفق جميع المدارس الاقتصـادية على أن السياسـة الماليـة هي مجموعـة مـن الاجر اءات التـي تقوم بها الحكومة بهذف التأثير في النشاط الاقتصادي وذللك من خلال استعمال أدو اتها كالإير ادات و النفقات و القروض من اجل تحقيق الاستقرار الاقتصادي ودفع عجلة التتمية والتوزيع العادل للاخول و الثروات. وفي الدول النامية والتي

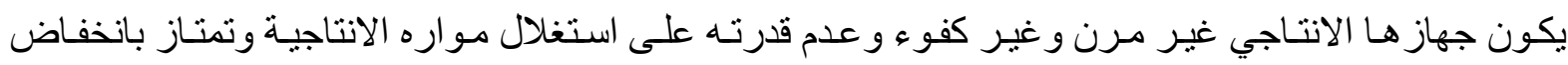
الاستثمار الانتاجي وارتفاع الميل الحدي للاستههلاك ، ممـا يقتضي ان التوسع في الطلب النقدي سوف ينعكس تضخماً . وكذللك تتميز هذه الدول بارتفاع نسبة العجز في الموازنة العامة للدولة الناجم عن ضعف الموارد المالية الضريبية نتيجة سبطرة حالـة الركود الاقتصـادي وكثرة الاعفـاءات و التهرب الضريبي من جهة ونمو الانفـاق العسكري و عدم ترشيد الانفاق العام من جهة أخرى وارتفاع نسبة الديون الداخلية والخارجية وهذا بدوره سوف يرفع المستوى العام للأسعار (التضخم) (؟).

\section{r- سعر الفائدة}

يعدُ معدل الفائدة واحداً من المتغيرات الاقتصـادية الكلية ذات الأهمية البالغـة في الاقتصـاد القومي، فهو يعد من أهم المؤشرات الاقتصادية التي تر اقب على نطاق واسع من قبل الأف من رجال الأعمال لآنها تؤثر في

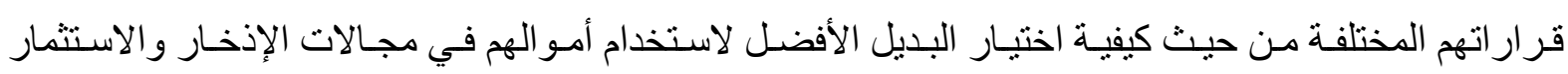

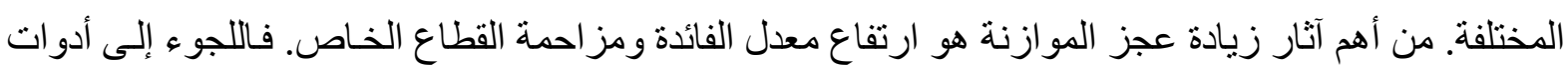

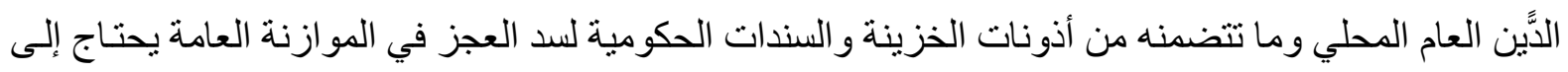

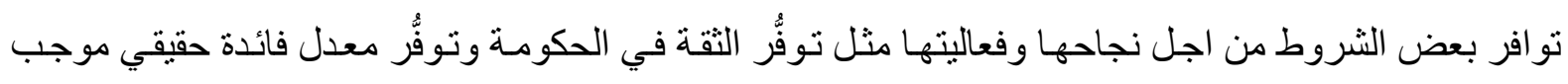
ومرتفع نسبياً، بالإضافة إلى توفر سوق نشطة للأور اق المالية. ولهذا تعتمد البلدان المتقدمة على هذه السياسة لسد العجز فيها، لأن تأثثر ها محدود على عرض النقد وعلى المستوى العام للأسعار وبالتالي ليس لها أثر تضخمي. ولكن في الدول النامية التي تلجأ إلى هذه الطريقة لسد العجز ولكن لا تتوفر فيها تلك الثـروط فتو اجهها مشكلة 
ارتفاع معدل التضخم وسلبية معدل الفائدة الحقيقي ولحل هذه المشـاكل تقوم الدول النامية بزيـادة معدل الفائدة الإسمي زيادة ملحوظة و إعفاء فو ائد أدوات الدين العام من الضر ائب على الدخل للتعويض عن الخسائر الممكنة

من ارتفاع مستوى الأسعار (־).

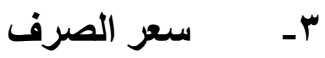

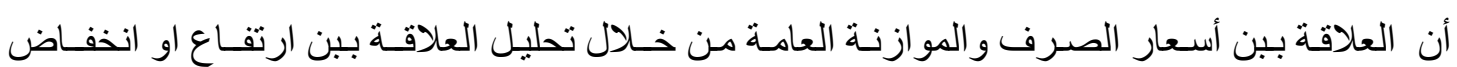

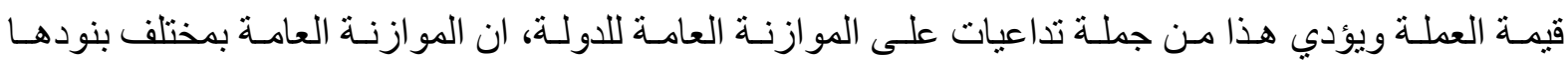

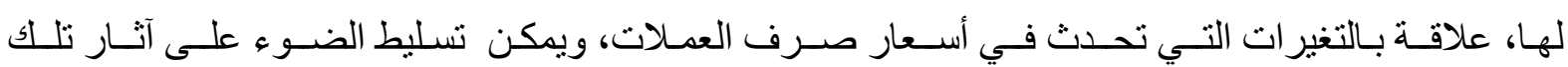
الحـالات على الموازنـة العامـة سـواء كانــت بـالعجز او الفـائض، ولهـذا الغـرض تركز الدر اسـة على حالتـان ارتفاع و انخفاض سعر الصرف و آثار هما على الموازنة العامة وكالاتي (').-

أ:-في حالة انخفاض أسعار الصـرف :- عند انخفاض سعر الصرف فـان هذا يؤدي الى ارتفـاع الأسعار

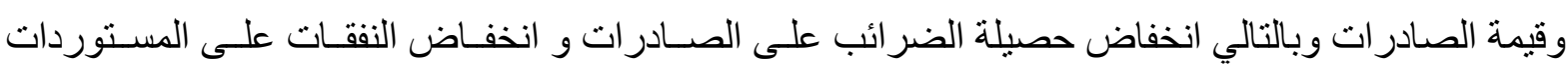

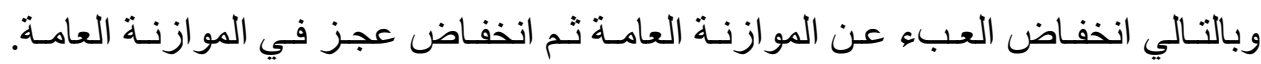
ب:-في حالـة ارتفـاع أسـعار الصـرف:- أن هنــالك علاقــة بــين أرتفــاع ســعر الصــرف وعجـز

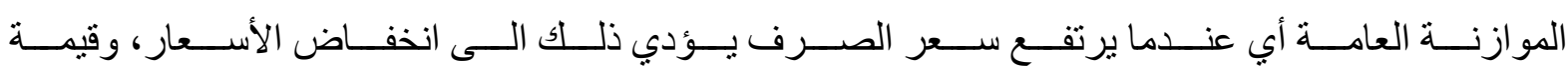
الصــادرات، وبالتــالي انخفـاض حصـيلة الضــر ائب علـى الصـادر ات و ارتفــاع قيمسـة الاسـتير ادات وزيــادة النفقات على المستوردات وبالتالي اثقال كاهل الموازنة العامة ثم ازدياد العجز في الموازنة العامة .

\section{ع ـمزاد العملة}

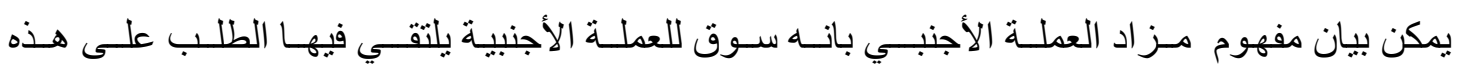

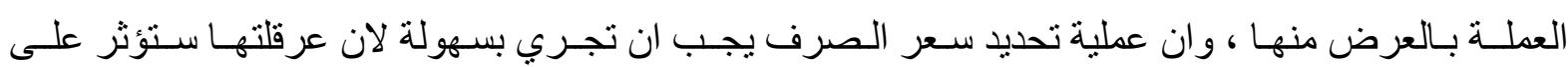
الطلب على العملـة الأجنبية (الدولار مثثلا) الـذي سـتتم عرقلتهـه سيشبع مـن الـسوق وسيكون هـذا الإشـباع بسعر صـرف أعلى وبالتـالي يحصل الارتباك في السوق ويكون هذا تمهيداً لتعدد أسعار الصرف، وبالتـالي

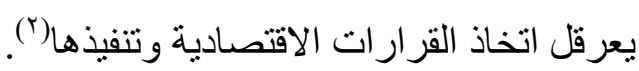
في الدول الريعية تكون الاير ادات النفطية تشكل نسبة كبيرة من موازنـة الدولـة العامـة وتسبطر عليها وز ارة المالية (الحكومة) أي تسيطر على العملة الاجنبية (الدولار) وتبيع للبنك المركزي العملـة المحلية وتكون نسبة مبيعات ومشتريات العملة مضطردة لانها تتاثر بأير ادات النفط و هي بدور ها عرضة لتقلبات اسعار النفط العالمية.

○-ميزان المدفوعات

المنهج الكنزي يقترح وجود علاقة مباثرة بين عجز الحساب الجاري و عجز الموازنة وهذا مـا يسمى بتو أمة العجزين، في حين أن عجز الموازنـة متغير خـارجي، وتفسير ذللك أن اتسـاع عجز الموازنـة يأتي نتيجـة

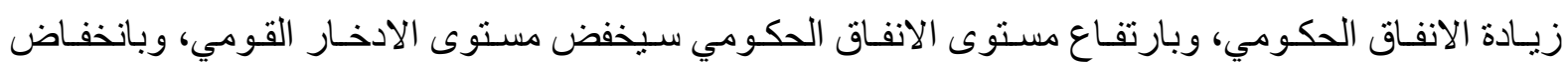


المدخر ات سترتفع سعر الفائدة وفي نظام سعر صرف مرن، سيرفع من طلب الاجانب على العملة المحلية سيرفع هذا بدوره سعر صرف العملة امام العملات الاجنبية ، وبالتالي تزداد الواردات وتقل الصـادرات وهذا يردي الى عجز بالميزان التجاري، وبالتالي يزداد عجز الحسـاب الجـاري ،وبذلك يؤدي عجز الموازنـة الى عجز الحسـاب

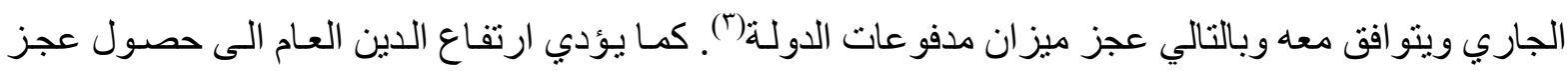

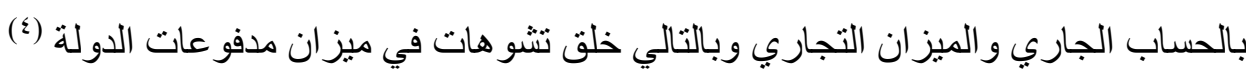

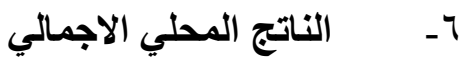

أن لأدوات السياسة المالية أثثار أ على الناتج المحلي الاجمالي فانخفاض عجز الموازنـة العامـة يؤدي الى لى

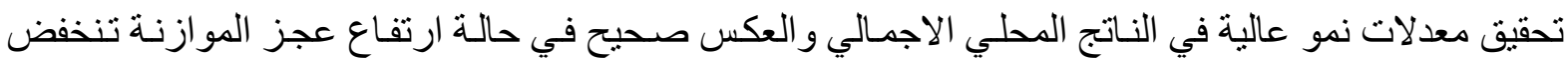
معدلات النمو في الناتج المحلي الاجمالي. وكذلك تؤثر النفقات العامة في الناتج المحلي الاجمـالي أذ كلمـا ارتفعت

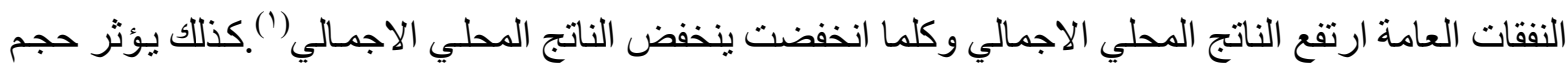
الدين العام في الناتج المحلي الاجمالي بشكل سلبي وايجابي ، فاذا ارتفعت نسبة الدين العـام عن( • \% \% ) فهذا يعني ان الاقتصاد الوطني سوف يو اجه مخاطر جمة وبالذات اذا استخدم الدين لأغر اض استههلاكية غير انتاجيـة

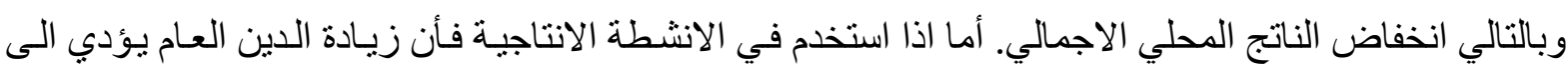
ارتفاع معدلات النمو في الناتج المحلي الاجمالي (؟). كما يؤدي ارتفاع النفقات العامة الى ارتفاع متزايد في الناتج المحلي الاجمالي في حالة توفر مرونة في الجهاز الانتاجي و العكس بالعكس.

الاستنتاجات والتوصيات

أولً:-الاستنتاجات

1 - ينصـرف مصـطلح الاسـتقلالية إلـى شـقين: الأول تعـد قـرارات اسـتخدام الأدوات التـي يتخـذها البنـلك

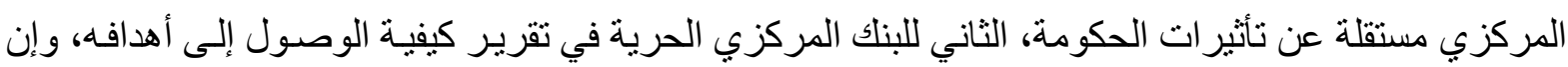
هذا لا يعني أن البنك المركزي يستطيع اختيار أهدافه بنفسـه، ففي النظـام الديمقر اطي يلاحظ انـه من المناسب للسلطات السياسية تمامـاً أن تضـع الأهداف العامـة للسياسـة الاقتصـادية ومن ثم يتوجـه البنك المركزي (الأكثر استقلالية) لمو اصلة تحقيقها، و هذا يعني أن البنك المركزي يكون مستقلا بأدو اته وليس مستقلا بأهدافه. ז - بسبب الظروف السياسية وتقلبات السوق النفطية ووضوح خطر السياسـات الاقتصـادية العامـة السـابقة تجددت الهيمنة المالية ليس بصيغتها القانونية بل بفعل الارثباط بين ميزانية البنك المركزي و الموازنة العامة.

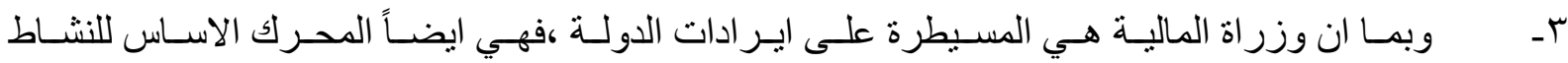
الاقتصادي في العراق، اذ تعتبر المتورد الرئيس لعناصر الطلب الكلي(الاستهلاك والاستثمار والانفاق الحكومي وصافي التجارة الخارجية.

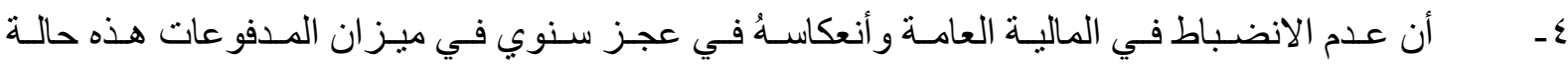
اللاستقر ار النسبي تدفع الى تخفيض الاحتياطـات الاجنبيـة بصورة تنعكس على السياسـة النقديـة لتحاول بدور ها تقييد المبيعات من النقد الاجنبي. 


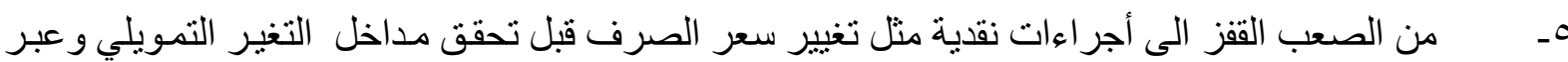
تعديل المالية العامة.

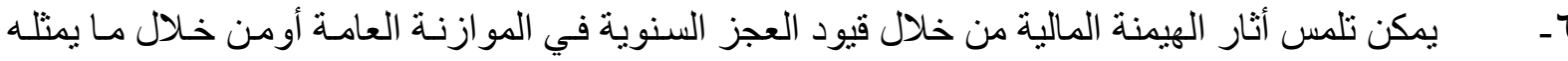
هذا العجز مـن دين داخلـي أو خـارجي والذي يتمثنل ايضـاً بالإصـدار ات مـن الســدات الـى جهات غير البنك المركزي(والديون لاى المؤسسات الاخرى ) اضافة الى الائتمان الذي يقدمه.

ثانياً:- التوصيات ا. على البنك المركزي العر اقي تحديد هدف و احد للسياسة النقدية نظر اً لظروف البلد الاقتصـادية ، لكي تَنُمّ مساءلة البنك المركزي العر اقي حول تحقيق هذا الهدف و لا يتم إلقاء اللوم نحو الأهداف الأخرى في حال تعدد أهداف السياسة النقدية.

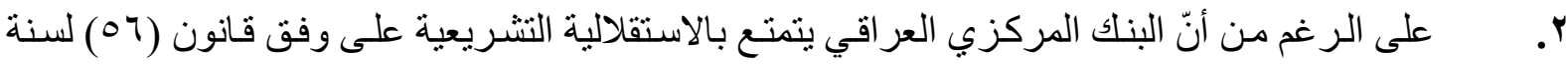
ع . . ب إلاّ أنّ من الو اجب علية التنسيق مع الحكومة لتصبح السياسة النقدية أكثر فعالية. r. على القائمين بأعمال المؤسسة النقدية الاهتمـام بـالمتغير ات الاقتصـادية ولاسيما أسعار الفائدة والتضخم وسعر الصرف، لان ذللك سوف يحدَّ من معدلات التضخم ويجعل العر اق بيئة استثمارية ملائمة. ع. أنْ يقوم البنك المركزي العر اقي بأخذ معدلات التضخم بالحسبان عند تحديد أسعار الفائدة الاسمية لكي

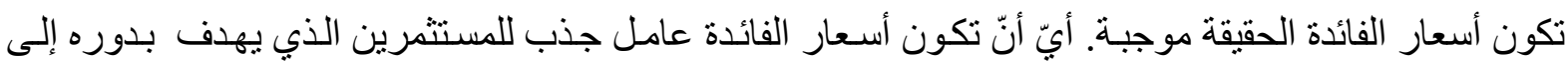
تحقيق عو ائد مالية.

ه. على السلطة التشريعية عدم التنخل في شؤون البنك المركزي العر اقي (من خلال تحديدها المبالغ التي تباع في

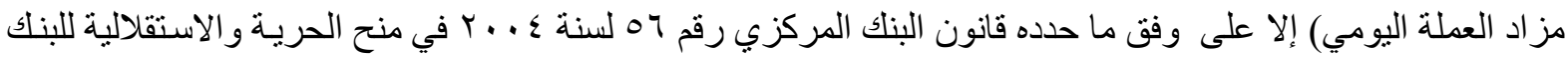
المركزي في تنفيذ السياسة النقدية و أنّ تقتصر وظيفة البرلمان على مساءلة وتعيين المحافظ على وفق ترشيح الحكومة.

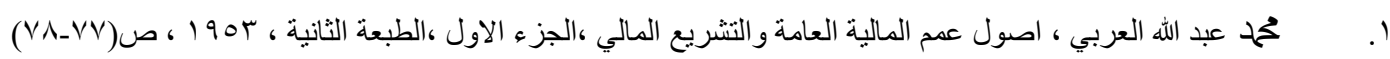

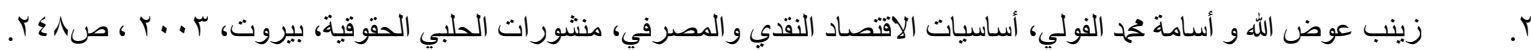

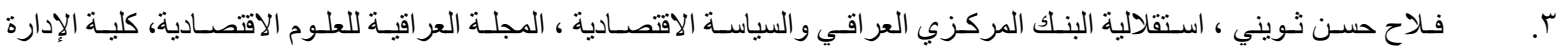

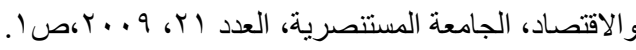
ع. سهام محمد السويدي ، استقلالية البنوك المركزية ودور ها في فعالية السياسة النقدية في الدول العربية ، الطبعة الأولى ، الدار الجامعية ،

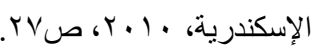

•. Carl E. Walsh, Central bank independence, University of California, Santa Cruz, USA, Web, r. • 0,Pr

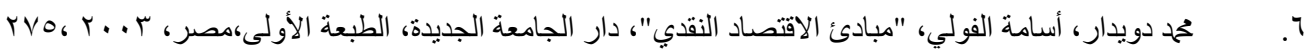
V. Dumiter, Florin Cornel. "Central Bank Independence and Inflation Targeting. The Case of Romania." Romanian Economic Journal ( $r \cdots q)$ p $/$ r

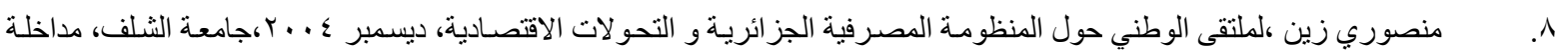

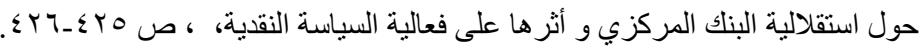


9. T T Mboweni, Central bank independence( Speech by Mr T T Mboweni, Governor of the South African Reserve Bank, at the Reuters Forum Lecture, held in Johannesburg, on 11 October $\uparrow \cdots$...)pp. $\ulcorner$.

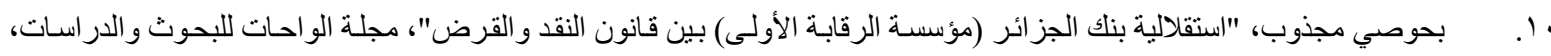

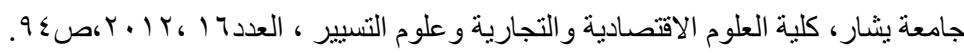

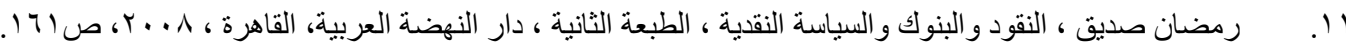

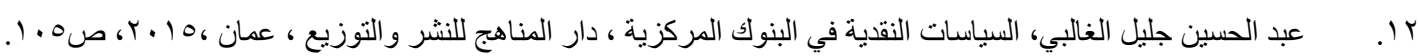

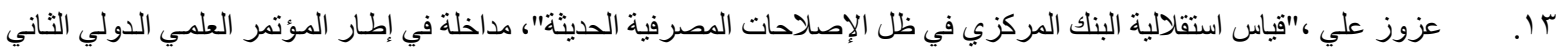

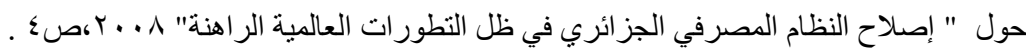

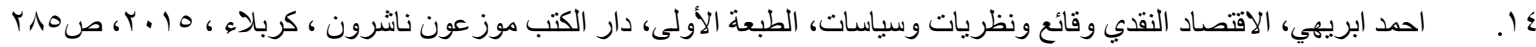

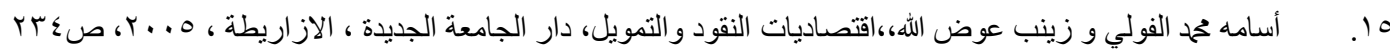

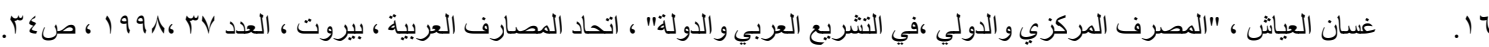

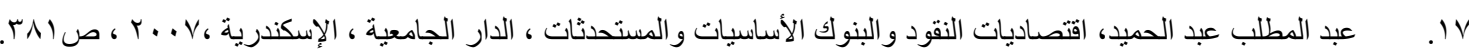

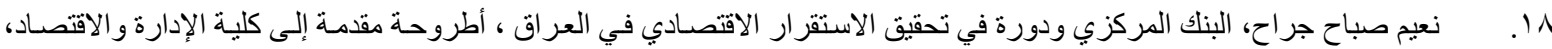

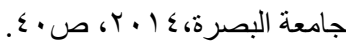

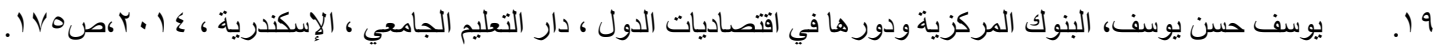

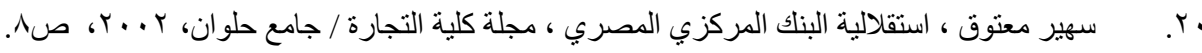

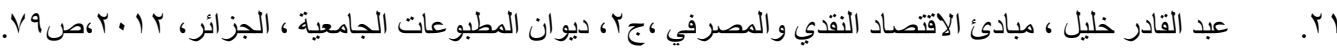

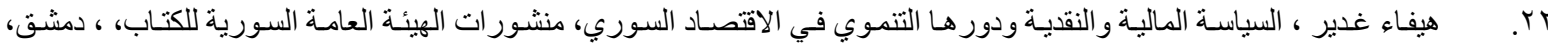

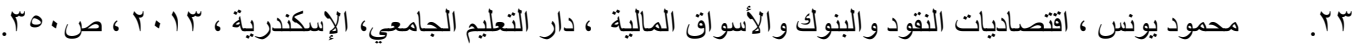

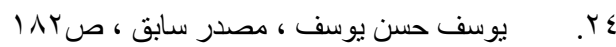

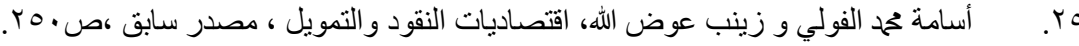

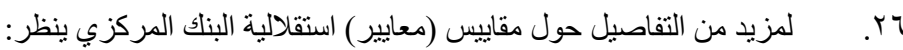

Yv. Thomas F. Cargill and Gerald P. O’Driscoll, Jr, Measuring Central Bank

५^. Independence, Policy Implications, and Federal Reserve Independence, University of Nevada, USA, $r \cdot 1$ r

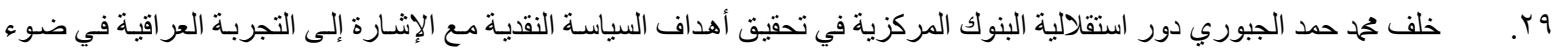

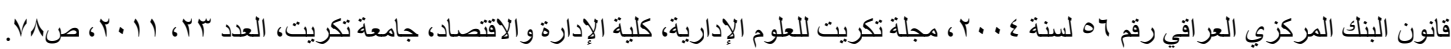

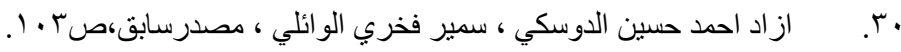

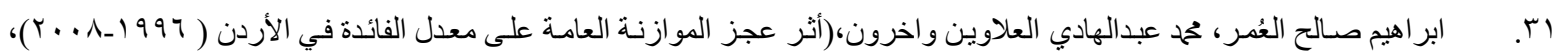

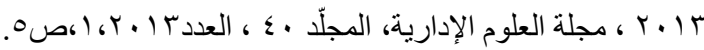

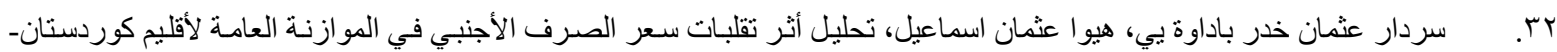

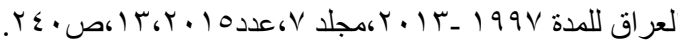

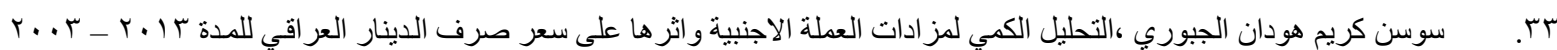

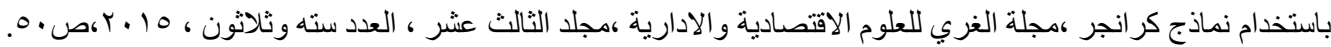

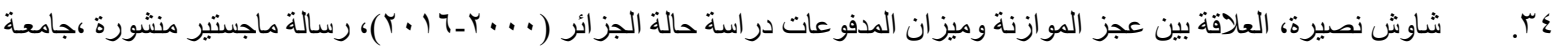

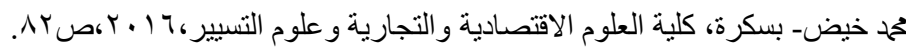

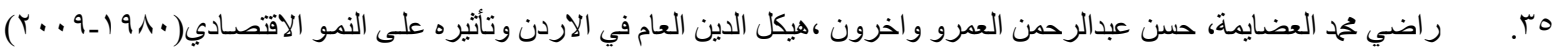

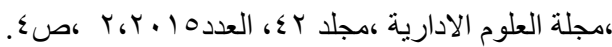

بس. مهدي سهر الجبوري، سلام كاظم شاني ، تحليل العلاقة السبيية بين عجز الموازنة العامـة والنـاتج المحلي الاجمالي في العراق للمدة

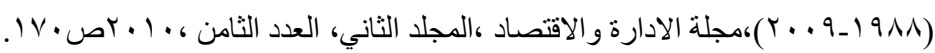

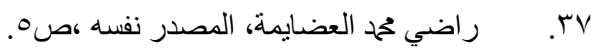

